\title{
Dragon multinationals powered by linkage, leverage and learning: A review and development
}

\author{
John A. Mathews ${ }^{1}$
}

Published online: 10 November 2017

(C) Springer Science+Business Media, LLC 2017

In the decade and a half since I introduced the term "dragon multinationals" to describe latecomer firms internationalizing from countries like Brazil, India and China (then called the "periphery" of the global economy) there have been astonishing changes in the international business system. The internationalizing firms themselves have proliferated, with many of them now becoming completely globalized and taking their place among the world's most advanced firms. From being latecomers dedicated to catch-up, many of them have now caught up and are moving from imitation to innovation. The core countries witnessing these changes have themselves assumed a stronger profile in world affairs (as the G20 takes over global leadership from the G7). And the strategic framework that I suggested underpins the success of internationalization efforts by latecomer multinationals, namely that they develop linkage, leverage and learning capabilities to accelerate their internationalization, has itself had to evolve and accommodate to the new circumstances. Scholars are now contributing refinements to the original framework that keep it relevant to fast-moving global conditions. In this paper I review these changes, pointing to the areas of continuity as well as some of the more significant refinements.

I first introduced the term "dragon multinational" in the book of that name, published in New York by Oxford University Press in 2002 - now a decade and a half ago. I revisited the term in the article published in 2006 by APJM, now just over a decade ago. So this Special Issue, and the conference on which it is based, has been a timely opportunity to review the relevance of the term "dragon multinational" and the continuing salience of the LLL strategic framework that underpins the notion. ${ }^{1}$

\footnotetext{
${ }^{1}$ It was a great honor to be asked by Professor Michael Carney, then Editor-in-Chief of Asia Pacific Journal of Management, to deliver the keynote address at the APJM conference in Sydney in December 2015. My thanks are due to Professor Mike W. Peng not only for his role as commissioning editor, but also for his role in ensuring that the article was nominated for and received the 2009 APJM Best Paper Award. It is gratifying to see that this is now my own most highly cited article (with just on 1433 citations in July 2017) and the journal's second most cited article after Geert Hofstede's 1984 article on international culture.
}

John A. Mathews

john.mathews@mgsm.edu.au

1 Macquarie Graduate School of Management, Macquarie University, Sydney, NSW 2109, Australia 
The question with which I started my 2006 APJM paper was: How does the global business system appear to a challenger firm, and how have challenger multinational enterprises (MNEs) from formerly peripheral areas such as the Asia Pacific established themselves successfully, against the sometimes fierce resistance of incumbents? My approach was to view such firms as new species in the "jungle" of international business, equipped with distinctive strategies that were designed to enable such firms to rapidly catch-up with incumbents. I sought to explain the success of these emergent dragon multinationals (henceforth, DMs) with their underlying strategy of linkage, leverage and learning (LLL) as a means of accounting for the accelerated internationalization of new firms going abroad from what was still called in the early 2000s the "periphery" of the world economy-from China, India, and the Asia Pacific. (Of course what was once known as the periphery is now becoming identified as the central core of the world economy.) This conceptual innovation was motivated by the need to provide a framework for making sense of the highly distinctive strategies being pursued by latecomer firms as they became active in the globalized economy. The essence of the idea is that such firms do not build their international empires entirely from their own resources and acquired capabilities but by linking with existing players and leveraging resources from them (technologies, assets, market positions) and doing so repeatedly. LLL appeared to be central features of the distinctive strategies that enabled firms to catch up with existing players through becoming active on the world stage.

Acer from Taiwan was the model for a DM - and Stan Shih, the founder and CEO, was the model DM strategist. I was given unrestricted access to Acer management, and engaged in highly rewarding discussions with Mr. Shih himself and his senior managers around the world as a I worked on my book Dragon Multinational. I am pleased to see that Dr. Shih-Chang Hung and his colleagues from the Institute of Technology Management in Taiwan are continuing the tradition of studying Acer as a model DM (Hung \& Tseng, 2017). The ways that Acer did things differently in order to capture potential latecomer advantages and turn them into real sources of advantage are indeed worthy of exploration - strategic innovations such as Acer's "fast food model" of local rapid assembling of PCs from components shipped both in bulk and to order, as well as Acer's creation of an interlinked group of firms closely interacting and supporting each other in a network emulating market relations within the group. The Acer phrase for this, adapted by Stan Shih from an old Chinese expression, is "Circle dragons no head"- a succinct account in four Chinese characters of a network organizational architecture suited for DMs. I was very pleased that Stan Shih provided me with these four characters drawn in his own calligraphy for the cover of my 2002 book.

Acer has now been joined by many other DMs - think of Chinese technology companies such as Lenovo in IT, Huawei in telecommunications and Geely in automotive (Guo, Li, \& Chen, 2017); the Indian steel company Ispat (now Arcelor-Mittal); white goods companies like Haier, wind power companies Goldwind and Suzlon; or the Mexican cement producer Cemex. In their different ways these firms have all demonstrated aspects of LLL in their patterns of internationalization. Ispat got its start on the road to becoming the world's largest steel company by licensing DRI technology from its Austrian developer - and scaling up the innovation to a degree not otherwise envisaged. Goldwind has now emerged as the world's largest promoter of Permanent Magnet Direct Drive (PMDD) technology which eliminates gearing and is especially suitable for offshore wind turbines - a technology leveraged from a small German 
company Vensys, now incorporated within the Chinese firm. Goldwind now specializes exclusively in PMDD machines - a smart latecomer strategy. For its part the white goods firm Haier was able to restart itself in 1985 in a joint venture (JV) with the German company Liebherr, thus gaining access to advanced technologies which it was quickly able to incorporate in its Chinese-made air conditioners and refrigerators. Haier has now gone on to become the world's best known Chinese brand. Cemex for its part was the world's first cement company to utilize global positioning satellite technology in order to keep track of its cement deliveries around the world.

These are the firms that are now emerging as outstanding cases to examine if we as scholars are to make sense of the key developments in the global economy driven by the successes of firms from the Asia Pacific. Critical to their successes have been strategies that involve various aspects of linkage (connecting up with existing players), leverage (securing technologies or other resources from these linkages) and learning (or repeated exercise of linkage and leverage activities) to enhance dynamic capabilities.

The key to LLL is that it provides a strategic framework that is focused on accelerated internationalization - creating a light, flexible lattice structure (another L) rather than a solid resource-heavy structure as in the traditional OLI modelin a way that draws on the interlinked character of the global economy. Let me briefly elaborate.

Linkage - Connecting with and making use of technology-rich companies or companies already active in target markets, taking advantage of the interlinked character of the global economy. Linkage can be effected through multiple channels. JVs are obviously one such pathway-but there are many others including supply chain contracts, technology licensing agreements, and partnerships focused on market entry. In all such cases, firms with a shortage of strategic resources can make up the deficiency by linking with existing players, provided they have the strategic intent to do so.

Leverage - Gaining access to technologies and/or market position as resources that lie outside the DM and which can be incorporated through smart strategies - strategies called by the scholars Gary Hamel and C.K. Prahalad "resource leverage" strategies in their famous Harvard Business Review article "Strategy as Stretch and Leverage" (1993). While Hamel and Prahalad saw the concept of resource leverage as being applied to leading firms in the lead countries, such as Cisco in Silicon Valley, I argued that the term actually covered the strategic aspirations of latecomers as well, and that cases involving these latecomers - the DMs - exemplified the process to a high degree of precision.

Learning - Or repeated application of linkage and leverage as a means of building the dynamic capabilities and global reach of the internationalizing firm, equipping it with the capabilities needed to withstand the competitive challenges imposed by established firms. Of course the notion of "learning" employed in the LLL framework is the least developed, and stands in need of further refinement based on an extensive body of research on organizational learning. In the context of latecomers internationalizing from emerging markets, specifically Indian pharma firms, Ray, Ray, and Kumar (2017) make a start in introducing such refinements.

Let me specify then how LLL reasoning differs from traditional OLI reasoning based as it is on timeless microeconomics logic. First, it is worth pointing out that LLL is indeed a strategic framework - compared with the traditional internationalization 
framework of OLI (based on prior possession of ownership, locational and internalization advantages). OLI is a timeless framework based on microeconomic reasoning, not strategic reasoning. It is surely about time that international business (IB) frameworks should explicitly call on strategic reasoning rather than microeconomics reasoning in developing a body of reliable knowledge.

A second feature of LLL as compared with traditional OLI reasoning is that it offers a strategy of catch-up to be utilized by latecomers as they seek to close the gap between themselves and advanced firms. Latecomers focus on accelerated internationalization because they cannot afford the luxury of leisurely internationalization — as described for example by the Uppsala model of incremental expansion. It is notable that the traditional OLI framework is silent on this crucial issue of time.

A third feature of LLL strategizing is that it is adapted to the interconnected, interlinked character of the global economy into which the new DMs are expanding. They thereby are enabled to build light, latticework organizational structures as they expand into markets around the world. By contrast the OLI framework ignores the substrate on which the process of internationalization unfolds.

In my view, these three features of LLL reasoning have stood up well to sustained scrutiny over the past decade and more. I describe LLL as a framework that can help IB scholars to make sense of the most important developments in our discipline. It is not a "model" with inputs and an output. It does not describe every case of a new multinational emerging from China or India. But what it does do is capture the most salient features of the firms that are emerging from what used to be called the periphery, insofar as it focuses on the key features of the catch-up strategies they usually employ and the key features of the interlinked character of the global economy that such firms can utilize as they formulate their distinctive latecomer strategies.

All MNEs can be said to enjoy OLI advantages - once they have expanded and become international in scale and scope. But to get there they have to deploy smart catch-up strategies that are framed by the specific technologies and specific markets they are targeting. They do not get there just through microeconomic reasoning. They have to strategize their way in a global world - and LLL provides them with a strategic framework adapted to their needs as latecomers. Of course, as they proceed to becoming global in their reach so their strategies need to evolve and with them, the conceptual frameworks we utilize to make sense of these strategies.

Indeed, there is so much interesting empirical research to be done utilizing the LLL framework - in production of individual cases (like Acer or Suzlon or Ispat) and in more generalized empirical investigation. Hao Tan and I have already begun this with work on the measurement of accelerated internationalization (Tan \& Mathews, 2015) as well as Professor Mei-Chih Hu with her work on the DMs' patent strategies (Hu, 2012). It's good to see LLL accepted so widely now in the IB if not yet in the strategy literature. And we can surely expect to see many more papers in APJM-including in this Special Issue devoted to DMs - employing the LLL framework and identifying yet more examples of successful DMs.

Many studies of internationalization from various countries have now appeared where LLL is a framework under study. Firms internationalizing from Turkey, for example, were studied by Demirbag, Tatoglu, and Glaister (2009); from Latin America by Ciravegna, Lopez, and Kundu (2016); and from India by Thite, Wilkinson, Budhwar, and Mathews (2016). Particular sectors such as white goods have also been 
the focus of studies employing the LLL framework, as in the study of DMs Koç from Turkey, Haier from China and Mabe from Mexico described by my colleagues Federico Bonaglia and Andrea Goldstein and myself in the Journal of World Business (2007). These studies will doubtless be amplified by further empirical work devoted to furthering the range of countries and industries studied.

Like all fresh strategic frameworks, LLL started life as a way of making sense of the internationalizing experience of a handful of emerging market firms emerging from industrializing countries in Asia. To become established as a framework in the discipline known as IB, it calls for empirical validation beyond the creation of case studies. A start is now being made in such empirical validation. Consider for example the study by $\mathrm{Li}$, Guo, and $\mathrm{Xu}$ (2017) of 321 Chinese firms internationalizing over the period 2000 to 2012. The focus of this study of patterns of internationalization in the twenty-first century is choice of entry mode into foreign markets by the firms-ranging from wholly-owned ventures at one extreme to full JVs at the other. The results of this study indicate that internationalizing firms from China that display strong LLL capabilities are more likely to choose the wholly-owned venture as entry mode over the JV mode. This may be interpreted to mean that firms that opt to build their own capabilities based on LLL as full-fledged players in the global arena are more likely to succeed in their internationalization than if they seek semi-permanent dependence on existing players via JVs. This is an interesting result in itself, and it also clarifies what firms are leveraging when they internationalize on the basis of LLL capabilities. They are not necessarily seeking to access resources via JVs. Instead they may be viewed as marshalling resources via technology transfer, licensing, acquisitions, and many other avenues - rather than simply utilizing the well-known avenue of seeking a JV partner. Further research is clearly needed on this point.

Likewise the study by Ray et al. (2017) of the internationalizing experiences of Indian pharma firms provides further support for the LLL framework as well as a useful refinement. These authors make a distinction between what they call "linkage and leverage" driven learning (at the early stages of the appearance of DMs) and what they characterize as later "autonomous" learning that is independent of capabilities acquired through linkage and leverage. This is a useful and empirically supported refinement that I have no quarrel with. Clearly if firms from the newly industrializing parts of the world are going to join the ranks of global leaders they have to do so on the basis of building their own autonomous capabilities as well as leveraging whatever they can from prior linkages (however these might be effected). The efforts at refinement by Ray et al. (2017) complement comparable efforts by Li $(2007,2010)$ to further elaborate on what he calls the unilateral and bilateral learning by latecomer multinationals. Earlier attempts to downplay LLL efforts by latecomers on the basis that they needed to have some prior capabilities in order to exercise LLL activities (e.g., Hennart, 2012; Narula, 2012) — never denied by me and simply taken for granted - are revealed as superficial when compared with a study such as that by Ray et al. (2017).

Further clarity is provided by Luo and Rui (2009) in an important article published in Academy of Management Perspectives. These authors posit an ambidexterity view 
on emerging market's firms' internationalization, where they see firms alternating between capturing OLI and LLL advantages. This certainly captures one important aspect of the original DM perspective, where firms are depicted as moving as rapidly as possible from catch-up and learning to exercising competitive advantages as traditionally conceived. But it is misleading insofar as it depicts emerging firms' strategic choices as moving between OLI and LLL advantages, as if they have freedom to make these choices. Originally my intention was to point to the need on the part of emerging market MNEs to engage in linkage and leverage as a means of bringing them abreast of established players (i.e., to catch up). It represents a strategic choice that would enable latecomers to accelerate their internationalization, not some free choice between LLL and OLI. To repeat, LLL provides a framework that makes sense of the catch-up efforts by latecomers, without impinging on whatever efforts they might be making to build their own autonomous capabilities.

\section{Conclusions}

In this brief paper I review the progress achieved and evolution of the conceptual strategic framework of LLL, offered at the beginning of the twenty-first century as a way of making sense of the distinctive strategies of newly emerging multinationals from newly emerging industrializing countries. As these firms and their points of departure in countries like China, India and Brazil have become more significant in the global economy, so the significance of the LLL framework as a way of explicating their strategic choices has also been enhanced. In the debate between myself and professors Dunning and Narula staged by this journal in 2006 (Dunning, 2006; Narula, 2006; Mathews, 2006a, 2006b), I was at pains to point out that I did not see LLL as a strategic framework displacing microeconomic reasoning of OLI, but rather as a way of complementing the timeless insights of OLI with the strategic necessities of latecomer firms that were seeking to become players in the globalized economy. This remains the case after a decade and a half of further development. Refinements have now appeared such as the need to distinguish between the learning in latecomers that is driven by linkage and leverage and the development of autonomous capabilities that enable these firms to power ahead to parity with global leaders. Others could no doubt be introduced that better integrate the notion of LLL reasoning within the scholarship on organizational learning. But the fundamental distinctive feature of LLL as a strategic framework, compared with OLI as based on timeless microeconomic reasoning, remains. These are the differences that can be expected to be reinforced as studies of DMs proliferate in IB in coming years.

\section{References}

Bonaglia, F., Goldstein, A., \& Mathews, J. A. 2007. Accelerated internationalization by emerging markets' multinationals: The case of the white goods sector. Journal of World Business, 42(4): 369-383.

Ciravegna, L., Lopez, L. E., \& Kundu, S. K. 2016. The internationalization of Latin American enterprises: Empirical and theoretical perspectives. Journal of Business Research, 69: 1957-1962.

Cuervo-Cazurra, A. 2012. Extending theory by developing country multinational companies: Solving the Goldilocks debate. Global Strategy Journal, 2(3): 153-167. 
Demirbag, M., Tatoglu, E., \& Glaister, K. W. 2009. Equity-based entry modes of emerging country multinationals: Lessons from Turkey. Journal of World Business, 44(4): 445-462.

Dunning, J. 1988. The eclectic paradigm of international production: A statement and some possible extensions. Journal of International Business Studies, 19(1): 1-31.

Dunning, J. H. 2006. Comment on dragon multinationals: New players in $21^{\text {st }}$ century globalization. Asia Pacific Journal of Management, 23(2): 139-141.

Guo, B., Li, Q., \& Chen, X. 2017. The rise to market leadership of a Chinese automotive firm: The case of Geely. In F. Malerba, S. Mani, \& P. Adams (Eds.). The rise to market leadership: New leading firms from emerging countries, Ch. 2: 20-42. Cheltenham: Edward Elgar.

Hamel, G., \& Prahalad, C. K. 1993. Strategy as stretch and leverage. Harvard Business Review, 71(2): 75-84.

Hennart, J.-F. 2012. Emerging market multinationals and the theory of the multinational enterprise. Global Strategy Journal, 2(3): 168-187.

Hu, M.-C. 2012. Technological innovation capabilities in the thin film transistor-liquid crystal display industries of Japan, Korea, and Taiwan. Research Policy, 41(3): 541-555.

Hung, S.-C., \& Tseng, Y.-C. 2017. Extending the LLL framework through an institution-based view: Acer as a dragon multinational. Asia Pacific Journal of Management, this issue.

Li, P. P. 2007. Toward an integrated theory of multinational evolution: The evidence of Chinese multinational enterprises as latecomers. Journal of International Management, 13(3): 296-318.

Li, P. P. 2010. Towards a learning-based view of internationalization: The accelerated trajectories of crossborder learning for latecomers. Journal of International Management, 16(1): 43-59.

Li, W., Guo, B., \& Xu, G. X. 2017. How do linking, leveraging and learning capabilities influence the entry mode choice for multinational firms from emerging markets?. Baltic Journal of Management, 12(2): 171193.

Luo, Y., \& Rui, H. 2009. An ambidexterity perspective toward multinational enterprises from emerging economies. Academy of Management Perspectives, 23(4): 49-70.

Mathews, J. A. 2002. Dragon multinational: A new model of global growth. New York: Oxford University Press.

Mathews, J. A. 2003. Competitive dynamics and economic learning: An extended resource-based view. Industrial and Corporate Change, 12(1): 115-145.

Mathews, J. A. 2006a. Dragon multinationals: New players in $21^{\text {st }}$ century globalization. Asia Pacific Journal of Management, 23(1): 5-27.

Mathews, J. A. 2006b. Responses to Professors Dunning and Narula. Asia Pacific Journal of Management, 23(2): 153-155.

Mathews, J. A., \& Zander, I. 2007. The international entrepreneurial dynamics of accelerated internationalization. Journal of International Business Studies, 38: 387-403.

Narula, R. 2006. Globalization, new ecologies, new zoologies, and the purported death of the eclectic paradigm. Asia Pacific Journal of Management, 23(2): 143-151.

Narula, R. 2012. Do we need different frameworks to explain infant MNEs from developing countries?. Global Strategy Journal, 2(3): 188-204.

Ray, P. K., Ray, S., \& Kumar, V. 2017. Internationalization of latecomer firms from emerging economies: The role of resultant and autonomous learning. Asia Pacific Journal of Management, this issue.

Tan, H., \& Mathews, J. A. 2015. Accelerated internationalization and resource leverage strategizing: The case of Chinese wind turbine manufacturers. Journal of World Business, 50(3): 417-427.

Thite, M., Wilkinson, A., Budhwar, P., \& Mathews, J. A. 2016. Internationalization of emerging Indian multinationals: Linkage, leverage and learning (LLL) perspective. International Business Review, 25 : $435-443$.

John A. Mathews (PhD, University of London) is a Professor of strategy at Macquarie Graduate School of Management, Macquarie University, Sydney. His research interests for the past two decades have been catchup strategies by latecomer firms, with special emphasis on firms in the Asia-Pacific region. More recently he has focused on greening strategies, as outlined in his webpage: www.globalgreenshift.org 